\title{
Tracing the Proposed Adverse Effects of Higher Values of Glycosylated Hemoglobin (HbA1c) in Tightly-Controlled Diabetic Patients Undergoing Primary CABG
}

\author{
Ahmed Saber Ibrahim Elsayed ${ }^{1}$, Khalid Ragab Abdelsamad Eid ${ }^{2}$ \\ ${ }^{1}$ Department of Cardiothoracic Surgery, Cairo University, Cairo, Egypt \\ ${ }^{2}$ Department of Cardiothoracic Surgery, Beni Suef University, Beni Suef City, Egypt
}

Email address:

ahmedsaber78@yahoo.com (A. S. I. Elsayed)

To cite this article:

Ahmed Saber Ibrahim Elsayed, Khalid Ragab Abdelsamad Eid. Tracing the Proposed Adverse Effects of Higher Values of Glycosylated Hemoglobin (HbAlc) in Tightly-Controlled Diabetic Patients Undergoing Primary CABG. International Journal of Cardiovascular and Thoracic Surger. Vol. 5, No. 2, 2019, pp. 31-40. doi: 10.11648/j.ijcts.20190502.12

Received: April 7, 2019; Accepted: May 23, 2019; Published: JuneM 5, 2019

\begin{abstract}
Objectives:The rising percentage of patients scheduled for primary $\mathrm{CABG}$ with $\mathrm{HbAlc}>8.6 \%$ is alarming reflecting higher burden on the patient, operative procedure and the operating surgeon. Although some articles in the literature argue that decompensated diabetes increases mortality and morbidity, other studies are arguing that there is no relation between them. This study aims at tracing the occurrence of the proposed adverse complications after primary CABG operations related to $\mathrm{HbA} 1 \mathrm{c}$ values $>8.6 \%$ in diabetics subjected to tight glycemic control; in a trial to conclude how far the value of HbA1c could be accepted to carry out the surgery safely. Methods:This prospective study included 80 adult diabetic patients who presented with IHD requiring primary CABG. It was conducted between January 2016 and December 2018. Group (I) included 42 patients with $\mathrm{HbA} 1 \mathrm{c}$ values $<8.6 \%$ and group (II) included 38 patients with $\mathrm{HbA} 1 \mathrm{c}$ values $>8.6 \%$. We compared the following: perioperative MI, low cardiac output syndrome, operative mortality, rhythmic complications, hemorrhagic complications, respiratory complications, cerebrovascular accidents, acute renal failure development, superficial and deep surgical wounds infections, overall hospital complications and overall one-year mortality and survival. Results: Mean $\mathrm{HbA1c} \%$ value was $7.5 \pm$ $1.11 \%$ for group (I) and $9.3 \pm 1.03 \%$ for group (II). Prior to surgery, the mean FBG level was $136.9 \pm 41.7 \mathrm{mg} / \mathrm{dl}$ for group (I) and $152.2 \pm 27.3 \mathrm{mg} / \mathrm{dl}$ for group (II) with tight glycemic control measures. Although group (II) showed higher values in the studied parameters (pre-, intra- and post-operatively), no statistically significant differences appeared between the two subsets of patients regarding the proposed adverse complications. The overall hospital complication rate was $13(30.95 \%)$ and $14(36.84 \%)$ for group (I) and (II) respectively ( $>0.05$ ). In the follow-up period, both groups expressed comparable results with no statistical significance. The overall one-year survival was $95.23 \%$ and $94.73 \%$ in group (I) and (II) respectively $(\mathrm{p}>0.05)$ and the overall mortality was $5 \%$ (two deaths from each group) ( $p>0.05)$. Conclusion:Although patients with IHD undergoing primary $\mathrm{CABG}$ and having decompensated diabetes with $\mathrm{HbAlc}$ values $>8.6 \%$ have more insulted cardiovascular condition, these higher HbAlc values do not add more additional impact on the proposed adverse intra- and postoperative complications as with lower values with the aid of strict (tight) glycemic control measures in the immediate preoperative period.
\end{abstract}

Keywords: Glycosylated Hemoglobin, HbAlc, Diabetic Primary CABG

\section{Introduction}

About $25-30 \%$ of patients undergoing primary Coronary Artery Bypass Grafting (CABG) surgery suffer from diabetes [1]. Generally, it is an independent risk factor for graft occlusion and cardiac deaths after myocardial revascularization. Moreover, the risk of micro- and macroangiopathy is higher when glycemia is poorly controlled [2]. Poor glycemia control in the perioperative period of the CABG surgery adversly affects the postoperative results [3]. On the contrary, it has been reported that postoperative outcomes improve in diabetic 
patients with a strict preoperative blood glucose control [4].

Glycemia control is measured by glycosylated hemoglobin A1c $(\mathrm{HbA} 1 \mathrm{c})$. It is formed when glucose in the blood binds irreversibly to hemoglobin to form a stable glycated hemoglobin complex. HbA1c test is a blood test used to measure the efficacy of antidiabetic therapy and, sometimes, to diagnose diabetes. A glycosylation reaction occurs when hemoglobin is exposed to blood sugar. The glycosylation reaction is defined as adherence of sugar molecules in the blood to hemoglobin, resulting in structural changes. During 120 days of erythrocyte lifespan, the rate of glycosylation of hemoglobin increases in parallel with the blood glucose levels. The HbAlc test measures the rate of glycosylation; therefore, HbAlc provides information about the blood glucose profile belonging to the erythrocyte lifespan, which is past 2-3 months $[5,6]$. The assessment of HbA1c level should be carried out using certified analytical methods recommended by the National Glycohemoglobin Standardization Program (NGSP), American (ADA) and European (EASD) Diabetes Associations [7]. Because $\mathrm{HbA1c}$ is one of the frequently used biomarkers that reflect high blood glucose values and poor glycemic control, it has been thought to be an ideal predictor in terms of postoperative outcome predictivity [8].

Preoperative high $\mathrm{HbA} 1 \mathrm{c}$ levels were found in $57 \%$ of non-diabetic patients and in $96 \%$ of diabetic patients who underwent $\mathrm{CABG}$ surgery [9]. Considering these high rates, mortality and postoperative complications should have been expected to be very high postoperatively. After the studies on HbA1c, which is reported to strongly predict mortality, publications suggesting that high $\mathrm{HbAlc}$ can predict postoperative adverse events but cannot reveal any presumption related to mortality started to become evident in the literature $[6,10]$. Moreover, it is even controversial whether or not high $\mathrm{HbA} 1 \mathrm{c}$ levels are a good biomarker for the development of diabetes. In high-risk patient groups, while the development of diabetes is probable in patients with $\mathrm{HbA} 1 \mathrm{c}>7.0 \%$, it is said that clinical diabetes does not develop within 10 years and is classified as false diabetes on the basis of this threshold criterion in approximately $20 \%$ of the low-risk patients with $\mathrm{HbAlc}$ levels $\geq 7.0 \%$ [11]. In addition, HbA1c levels in the form of mild glucose intolerance significantly overlap with Fasting Blood Glucose (FBG) values. While this dispute continues between HbA1c level elevation and prediction of diabetes development, there are conflicting results regarding whether or not HbAlc level elevation is predictive for the risk of cardiovascular events [12].

Some researchers suggest that a decrease in the previously elevated level of $\mathrm{HbA} 1 \mathrm{c}$ can be demonstrated even within 2 weeks of a change in therapy [13]. Additionally, although the European System for Cardiac Operative Risk Evaluation (EuroSCORE) did not identify diabetes as a risk factor for cardiac surgical mortality [14], the newerEuroSCORE II launched in October 2011 and the American STS SCORE do include diabetes in the risk factors. The STS SCORE also associates different risks based on how the patient is treated.
However, no cardiac surgical risk scale mentions glycosylated hemoglobin (HbA1c)[15].

It has been claimed that high HbAlc levels are a strong predictor of mortality and morbidity independently of the patient's previous diabetic condition, and the mortality risk increases four-fold especially in coronary surgery cases when HbA1c levels are $>8.6 \%$ [16]. Although some articles in the literature argue that high $\mathrm{HbA1c}$ levels $>8.6 \%$ increase mortality and morbidity, there are studies arguing that there is no relation between them. However, the rising higher percentage of primary $\mathrm{CABG}$ patients with decompensated diabetes (patients with $\mathrm{HbAlc}>8.6 \%$ ) is alarming [6].

Based on this, this study is conducted to trace the occurrence of the proposed unfavourable adverse complications that are expected to happen after primary CABG operations related to $\mathrm{HbA1c}$ values higher than $8.6 \%$ in diabetic patients subjected to tight (strict) blood glucose level control using insulin therapy in a trial to conclude how far the value of $\mathrm{HbAlc}$ could be accepted to carry out the surgery safely.

\section{Patients and Methods}

\subsection{Study Design}

This prospective comparative study included 80adult diabetic patients who presented with ischemic heart disease (IHD) requiring primary surgical myocardial revascularization (primary $\mathrm{CABG}$ surgery). The study was conducted after obtaining a written informed consent of each and every participant. All the surgeries were carried out in Egypt (conducted in operating theatre of the Department of Cardiothoracic Surgery, Faculty of Medicine, Cairo University; and other open heart surgery centers) using standard open heart surgical procedures. The study was conducted in the period between January 2016 and December2018. The study population was divided into two groups based on their most recent test of HbA1c\%. Group (I)included 42 patients with HbAlc values less than $8.6 \%$ and group (II)included38patientswith $\mathrm{HbA1c}$ values more than $8.6 \%$ (decompensated diabetes). The data of the study population was collected from the cardiothoracic section computer database supplemented by a review of hospital records. All the data were studied and thoroughly evaluated in the preoperative, intraoperative and postoperative periods (for one year).

\subsection{Inclusion and Exclusion Criteria}

The study population included adult diabetic patients scheduled for elective primary CABG surgery presenting with multi-vessel coronary artery disease, left main or left mainequivalent coronary artery disease and one or two coronary artery disease. We excluded patients with concomitant valvular heart disease (due to any aetiological factor including ischemic mitral valve disease), patients with history of previous cerebrovascular stroke, patients with multiple co-morbidities e.g. liver cell failure, renal failure, respiratory failure, malignancy, and 
patients with left ventricular ejection fraction (LVEF) less than $40 \%$. Also, we excluded patients with associated pathologies such as ascendingaortic aneurysm/dissection, left ventricular aneurysm, and ventricular septal defects.

\subsection{Management Regimen}

\subsubsection{Preoperatively}

The collected preoperative data from the study population were age, sex, risk factors of cardiovascular disease e.g. hypertension, smoking, dyslipidemia, post-menopause, and family history of susceptibility to IHD, previous myocardial infarction (MI) and history of CCU admission, history of coronary angioplasty and stenting, left ventricular ejection fraction (LVEF), EuroSCORE II and history of chronic renal disease and peripheral vascular disease. History of being diagnosed as a diabetic patient (duration, antidiabetic agents received whether oral or insulin therapy and regularity of blood glucose level follow-up)was stressed upon. Most recent HbA1c levels were examined and recorded. All the study group population weresubjected to strict (tight) glycemic control measures using different doses of insulin therapy (individualized based on endocrinological consultations)for the preoperative 710 days period aiming to keep blood glucose measures 110-150 $\mathrm{mg} / \mathrm{dl}$. This included combination of scheduled subcutaneous insulin therapy and repeated insulin injections according to Matias protocol [17]. Hypoglycemia was defined as a blood glucose level below $70 \mathrm{mg} / \mathrm{dl}(3.9 \mathrm{mmol} / \mathrm{l})$ and hyperglycemia as a blood glucose level above $250 \mathrm{mg} / \mathrm{dl}$ (13.9 mmol/l). Acetylsalicylic acid was discontinued 5 days before surgery while clexaneand clopidogril were discontinued 12 hours and 57 daysrespectively before it. All patients received sedative premedications (oral valium $5 \mathrm{mg}$ at the night of surgery and intramuscular morphia $10 \mathrm{mg}$ at the morning of surgery) as surgical stress is a known cause of diabetes imbalance.

\subsubsection{Intraoperatively}

Operative technique was always the same for all the study population. All the patients were operated upon via standard vertical median sternotomy, cardiopulmonary bypass (CPB) was initiated withaorto-cavalcannulation, ascending aorta was cross clamped and cardioplegia was received by warm blood intermittent antegrade technique every 20 minutes. Pedicled left internal thoracic (mammary) artery (LIMA) was always anastomosed to left anterior descending coronary artery (LAD) and harvested reversed saphenous vein grafts (SVGs) were anastomosed to other target coronaries. Proximal anastmoses were carried out after hot shot dose and unclamping the aorta regaining myocardial activity using partial aortic side occlusion clamping. The intraoperative variables included intraoperative mortality, aortic cross clamping time, CPB time, number ofgrafts done, blood glucose level (during and after CPB), metabolic acidosis, haemodynamics, weaning off-CPB, inotropic support medications and intra-aortic balloon insertion. Again, all the patients were subjected to intra-operative tight (strict) glycemic control using uniform intravenous insulin infusion protocol (prepared by mixing 100 units of insulin with $50 \mathrm{ml} 0.9 \%$ Normal Saline) aiming to keep blood glucose measures 110-150 mg/dl. Frequent measurements of blood glucose as well as $\mathrm{pH}$ value were obtained from serial arterial blood samples taken every 15 minutes.

\subsubsection{Postoperatively}

After transferring the patients to the intensive care unit (ICU), glucose levels and $\mathrm{pH}$ value were obtained from arterial blood samples every 2 hours. Again, patients received a continuous insulin infusion during all the period of ICU stay to maintain blood glucose levels $110-150 \mathrm{mg} / \mathrm{dl}$. And once the patients were transferred to the zone area or regular room, blood glucose values were obtained every 4-6 hours and subjected to strict (tight) glycemic control measures using different doses of insulin therapy (individualized) aiming to keep blood glucose measures $110-150 \mathrm{mg} / \mathrm{dl}$ via combination of scheduled subcutaneous insulin therapy and repeated insulin injections according to Matias protocol [17]. After discharge, patients were followed-up for one year postoperatively. The postoperative variables included operative mortality and adverse complications. We studied and compared the following outcome parameters in both groups:Perioperative myocardial infarction was defined as creatinine kinase-MB elevation of 5 or more times the upper limit of normal and the presence of any new $Q$ wave within 48 hours postoperatively or the disappearance of the $\mathrm{R}$ wave on the postoperative electrocardiogram (ECG). Low cardiac output syndrome was defined as the need for the use of two catecholaminesbeyond $10 \mathrm{microgram} / \mathrm{Kg} / \mathrm{min}$ dose or the use of an intra-aortic balloon pump (IABP). Operative mortality was defined as any death occurring during the 30 days postoperatively. Rhythmic complications weredefined by the presence of a supraventricular or ventricular rhythm disorder. Hemorrhagic complications were defined by re-operation to controlbleeding or to relieve cardiac tamponade. Respiratory complications were defined by the development of pneumonia, pulmonary atelectasis, and respiratory failure (prolonged ventilation more than 24 hours postoperatively, re-intubation or tracheotomy). Cerebrovascular accident was defined as a new stroke or a transient ischemic attack (TIA) for at least 24 hours. Acute renal failure was defined as a rise in the creatinine level (absolute $\geq 0.3 \mathrm{mg} / \mathrm{dl}$, percentage $\geq 50 \%$ ) in need for renal replacement therapy or the need for dialysis sessions (excluding patients requiring dialysis before the operation). Preoperative chronic renal failure was defined as a creatinine clearance of less than $30 \mathrm{ml} / \mathrm{min}$. Preoperative peripheral vascular disease was defined as the presence of lower limb arterial disease stage I or II according to Leriche and Fontaine classification or a history of vascularsurgery. Deep surgical wounds (sternal and lower limbs) infections were defined as a surgicalinfection occurring within 30 days, extending beyond the deep tissue plane with bacteriological samples of positive infected tissues or purulent discharge. The overallhospital complication rate was calculated on the basis of the number of patients with at least one hospital complication.

\subsection{Statistical Analysis}

All patients' data were tabulated and processed using SPSS V10.0 (SPSS Inc., Chicago, IL) for Windows 2007. Quantitative 
variables were expressed using mean and standard deviation, and were compared using $t$-student test. Qualitative variables were compared using Chi-square test or Fischer's exact test when appropriate. Correlation between parameters was performed using Spearman's rank correlation coefficient. In all tests, $P$ value was considered significant when $P<0.05$, highly significant when $P<0.01$ and extremely significant when $P<0.001$.

\section{Results}

In the period betweenJanuary 2016 and December 2018, this study was conducted on 80adult diabetic patients undergoing primary CABG. The study population was divided into two groups based on their most recent test of $\mathrm{HbA} 1 \mathrm{c} \%$. Group (I)included 42 patients with $\mathrm{HbAlc}$ values less than $8.6 \%$ and group (II)included 38 patients with $\mathrm{HbAlc}$ values more than $8.6 \%$ (decompensated diabetes). The preoperative, operative, postoperative and one-year follow-up data of both groups were thoroughly studied and compared.

\subsection{Preoperative Data}

The study included 30(37.5\%)men and 50(62.5\%)women (all the ladies were post-menopausal) whose ages ranged from 50 to 69 years with a median age of 62.5 years. There were 24 females
(57.14\%) in group (I) as compared to 26 females $(68.42 \%)$ in group (II). The mean age for group (I) patients was $60.34 \pm$ 6.81 years and for group (II) $61.65 \pm 6.53$ years. All patients had undergone a thorough clinical evaluation which included proper history taking, general, chest and cardiac examination. Mean period of diagnosing and receiving treatment of diabetes mellitus was $20.41 \pm 2.32$ yearsfor group (I) and $20.91 \pm 1.56$ years for group (II). Mean $\mathrm{HbA1c} \%$ value was $7.5 \pm 1.11 \%$ (range 7.00-8.6\%)for group (I) and $9.3 \pm 1.03 \%$ (range 8.6 $10.3 \%$ )for group (II) representing high statistical significance $(p<0.01)$. Prior to hospital admission, insulin preparation therapy was received by $47.62 \%$ of group (I) patients and $44.74 \%$ of group (II) patients. Both groups were subjected to strict (tight) glycemic control measures using different doses of insulin therapy (individualized based on endocrinological consultations) for the preoperative 7-10 days period aiming to keep blood glucose measures 110-150 mg/dl. This included combination of scheduled subcutaneous insulin therapy and repeated insulin injections according to Matias protocol [17]. Prior to surgery, the mean FBG was $136.9 \pm 41.7 \mathrm{mg} / \mathrm{dl}$ for group (I) and $152.2 \pm 27.3$ $\mathrm{mg} / \mathrm{dl}$ for group (II) with nostatitical significance $(p>0.05)$. No patient of either group needed preoperative intra-aortic balloon insertion. Further analysis of the preoperative patients' characteristics and laboratory investigationsof both groups are summarized in Table 1.

Table 1. Preoperative Patients' Characteristics and Laboratory Investigations (Data were expressed as mean \pm standard deviation (SD) or number (\%), NS= Not Significant, $t=$ Test of significance).

\begin{tabular}{|c|c|c|c|c|c|}
\hline & Group (I) $(n=42)$ & Group (II) $(n=38)$ & $\mathbf{t}$ & $P$ value & Significance \\
\hline Age (years) & $60.34 \pm 6.81$ & $61.65 \pm 6.53$ & 0.84 & $>0.05$ & NS \\
\hline Female/Male & $24 / 18(57.14 / 38.46 \%)$ & $26 / 12(68.42 / 31.58 \%)$ & 0.85 & $>0.05$ & NS \\
\hline Longivity of D.M.(years) & $20.41 \pm 2.32$ & $20.91 \pm 1.56$ & 0.81 & $>0.05$ & NS \\
\hline $\mathrm{HbA} 1 \mathrm{c} \%$ value & $7.5 \pm 1.11$ & $9.3 \pm 1.03$ & 8.52 & $<0.01$ & Highly Significant \\
\hline Insulin therapy(years) & $20(47.62 \%)$ & $17(44.74 \%)$ & 0.57 & $>0.05$ & NS \\
\hline Positive family history of IHD & $11(26.19 \%)$ & $13(34.21 \%)$ & 0.58 & $>0.05$ & NS \\
\hline Smoking & $20(47.61 \%)$ & $20(52.63 \%)$ & 0.55 & $>0.05$ & NS \\
\hline Dyslipidaemia & $27(64.29 \%)$ & $28(73.68 \%)$ & 0.85 & $>0.05$ & NS \\
\hline Previous MI & $18(42.85 \%)$ & $22(57.89 \%)$ & 0.85 & $>0.05$ & NS \\
\hline History of CCU admission & $14(33.33 \%)$ & $19(50.00 \%)$ & 0.81 & $>0.05$ & NS \\
\hline History of PCI and stenting & $12(28.57 \%)$ & $15(39.47 \%)$ & 0.83 & $>0.05$ & NS \\
\hline LVEF\% & $54.2 \pm 5.1$ & $53.6 \pm 7.5$ & 0.37 & $>0.05$ & NS \\
\hline EuroSCORE II & $1.1(0.77-1.38)$ & $1.4(0.76-1.68)$ & 0.88 & $>0.05$ & NS \\
\hline Chronic renal disease & $1(2.38 \%)$ & $2(5.26 \%)$ & 0.85 & $>0.05$ & NS \\
\hline Left main or LM equivalent disease & $18(42.85 \%)$ & $20(52.63 \%)$ & 0.85 & $>0.05$ & NS \\
\hline Three or more coronary disease & $27(64.29 \%)$ & $28(73.68 \%)$ & 0.85 & $>0.05$ & NS \\
\hline Less than three coronary disease & $15(35.71 \%)$ & $10(26.32 \%)$ & 0.85 & $>0.05$ & NS \\
\hline PT & $14.41 \pm 0.7$ & $14.28 \pm 0.6$ & 0.76 & $>0.05$ & NS \\
\hline $\mathrm{PC}$ & $74 \pm 4.8$ & $74.5 \pm 3.7$ & 0.42 & $>0.05$ & NS \\
\hline INR & $1.28 \pm 0.08$ & $1.29 \pm 0.06$ & 0.18 & $>0.05$ & NS \\
\hline ALT & $35.1 \pm 13.9$ & $39.7 \pm 5.5$ & 1.7 & $>0.05$ & NS \\
\hline AST & $37.4 \pm 11.2$ & $36.97 \pm 9.4$ & 0.17 & $>0.05$ & NS \\
\hline Bilirubin & $0.66 \pm 0.2$ & $0.69 \pm 0.15$ & 0.66 & $>0.05$ & NS \\
\hline Albumin & $4.18 \pm 0.3$ & $4.34 \pm 4.3$ & 0.21 & $>0.05$ & NS \\
\hline Creatinine & $0.96 \pm 0.19$ & $1.01 \pm 0.15$ & 1.23 & $>0.05$ & NS \\
\hline Urea & $46.3 \pm 9.8$ & $49.3 \pm 9.1$ & 1.46 & $>0.05$ & NS \\
\hline Sodium & $138.8 \pm 4.4$ & $138.2 \pm 4.6$ & 0.55 & $>0.05$ & NS \\
\hline Potassium & $4.2 \pm 0.6$ & $4.4 \pm 0.5$ & 1.4 & $>0.05$ & NS \\
\hline FBG(on admission) & $217.8 \pm 31.1$ & $233.3 \pm 19.1$ & 0.67 & $>0.05$ & NS \\
\hline FBG(just prior to surgery) ) & $136.9 \pm 41.7$ & $152.2 \pm 27.3$ & 0.77 & $>0.05$ & NS \\
\hline
\end{tabular}




\subsection{Operative Data}

All patients of both groups were submitted for primary CABG using the same technique of graft anastmosis with pedicled LIMA to LAD and reversed SVGs for other coronary artery targets with the help of heart-lung machine and antegradewarm blood intermittent cardioplgia given every 20 minutes. All the patients were subjected to intraoperative tight (strict) glycemic control using uniform intravenous insulin infusion protocol (prepared by mixing 100 units of insulin with $50 \mathrm{ml} 0.9 \%$ Normal Saline) aiming to keep blood glucose measures $110-150 \mathrm{mg} / \mathrm{dl}$. Frequent measurements of blood glucose as well as $\mathrm{pH}$ value were obtained from serial arterial blood samples taken every 15 minutes. No intra-operative mortality happened as well as no intra-aortic balloon was needed to assist haemodynamics. Metabolic acidosis was encountered and continuously corrected in $28.57 \%$ and $34.21 \%$ of group (I) and (II) respectively, yet it was controlled before transferring patients to ICU and no one faced persistant acidosis. All patients were transferred to ICU on epinephrine infusion 5 microgram $/ \mathrm{kg} / \mathrm{min}$. as a supportive physiological dose for the initial 24 hours postoperatively. However, norepinephrine was added to $33.33 \%$ and $39.47 \%$ of group (I) and (II) respectively to control diabetic vasculopathy (vasoplegia). Haemodynamic parameters during the operation were recorded showing no significant differences among both groups. Smooth weaning off-bypass was achieved in 35 patients $(83.33 \%)$ of group (I) and 31 patients $(81.58 \%)$ of group (II) $(p>0.05)$. The rest of the patients needed electrical cardioversion to achieve weaning. The date of the operation was recorded and the operative reports for both groups were assessed and the data recorded, analysed and compared. The data are shown in Table 2.

Table 2. Operative Data (Data were expressed as mean \pm standard deviation (SD)or number (\%), NS= Not Significant, $t=$ Test of significance)

\begin{tabular}{|c|c|c|c|c|c|}
\hline & Group (I) $(n=42)$ & Group (II) (n= 38) & $\mathbf{t}$ & $p$ value & Significance \\
\hline Total operation time (min) & $190.23 \pm 23.56$ & $197.11 \pm 33.55$ & 0.82 & $>0.05$ & NS \\
\hline Total bypass time (min) & $103.38 \pm 11.24$ & $111.29 \pm 28.83$ & 0.80 & $>0.05$ & NS \\
\hline Total cross clamp time (min) & $63.47 \pm 21.53$ & $71.30 \pm 25.74$ & 0.79 & $>0.05$ & NS \\
\hline LIMA-to-LAD anastmosis & $42(100 \%)$ & $38(100 \%)$ & 0.00 & $>0.05$ & NS \\
\hline Three or more coronary targets & $27(64.29 \%)$ & $28(73.68 \%)$ & 0.85 & $>0.05$ & NS \\
\hline Less than three coronary targets & $15(35.71 \%)$ & $10(26.32 \%)$ & 0.85 & $>0.05$ & NS \\
\hline Metabolic Acidosis & $12(28.57 \%)$ & $13(34.21 \%)$ & 0.86 & $>0.05$ & NS \\
\hline Glucose level (after CPB) )(mg/dl) & $210.5 \pm 21.8$ & $221.6 \pm 36.1$ & 0.87 & $>0.05$ & NS \\
\hline Norepinephrine & $14(33.33 \%)$ & $15(39.47 \%)$ & 0.86 & $>0.05$ & NS \\
\hline Smooth weaning-off CPB & $35(83.33 \%)$ & $31(81.58 \%)$ & 0.85 & $>0.05$ & NS \\
\hline
\end{tabular}

\subsection{Postoperative Data}

All the patients were discharged to the ICU mechanically ventilated. Blood glucose levels and $\mathrm{pH}$ value were obtained from arterial blood samples every 2 hours. Again, patients received a continuous insulin infusion during all the period of ICU stay to maintain blood glucose levels at $110-150 \mathrm{mg} / \mathrm{dl}$. Patients were discharged from the ICU when haemodynamically stable on no inotropic support, with no drains and with satisfactory postoperative laboratory results and ECG. The mean period of the total ICU stay was $2.52 \pm$ 0.4 days for group (I) patients and $2.77 \pm 0.3$ days for group (II) patients $(p>0.05)$. And once the patients were transferred to the zone area or regular room, blood glucose values were obtained every 4-6 hours and subjected to strict (tight) glycemic control measures using different doses of insulin therapy (individualized) aiming to keep blood glucose measuresat $110-150 \mathrm{mg} / \mathrm{dl}$ via combination of scheduled subcutaneous insulin therapy and repeated insulin injections according to Matias protocol [17]. The mean duration of the total hospital stay (in days) was 8.24 in group (I) and 8.47 in group (II) $(p>0.05)$. There were a total of $2(2.5 \%)$ mortality cases, $1(2.38 \%)$ in group (I) and $1(2.63 \%)$ in group (II) $(p>0.05)$. All of them happened in the postoperative ICU period due to heart failure. Atrial Fibrillation (AF) occurred in $7(16.66 \%)$ and $8(21.05 \%)$ of group (I) and (II) respectively $(p>0.05)$. Nocerebrovascular accidents were faced in either group. No statistically significant differences were found regarding the total duration of mechanical ventilation, inotropic support duration, total blood loss, perioperative MI, low cardiac output syndrome, rhythmic complications, haemorrhagic complications, cerebrovascular accidents, deep surgical wound infection, superficial surgical wound infection, respiratory complications, acute renal failure and need of postoperative IABP insertionas been shown in Table 3. The overallhospital complication rate was $13(30.95 \%)$ and $14(36.84 \%)$ for group (I) and (II) respectively $(p>0.05)$. After hospital discharge, patients were followed-up for one year. Patients were called after a mean period of $340.09 \pm 12.37$ days in group (I) and $341.97 \pm$ 15.98 days in group (II) $(p>0.05)$. The mean period for return to work was $55.23 \pm 14.81$ days in group (I) and $57.93 \pm$ 11.67 days in group (II) $(p>0.05)$. Two more mortality cases happened during the follow-up period (one in each group). One patient $(2.63 \%)$ of group (II) experienced persistent superficial wound infection of both sternum and lower limbs (due to intolerance of blood glucose level control measures and regular follow-up) which responded to frequent dressings. 
Table 3. Postoperative ICU data (Data were expressed as mean \pm standard deviation (SD), NS= Not Significant, $t=$ Test of significance).

\begin{tabular}{|c|c|c|c|c|c|}
\hline & Group (I) $(n=42)$ & Group (II) (n= 38) & $\mathbf{t}$ & $p$ value & Significance \\
\hline Duration of mechanical ventilation (hrs) & $6.1 \pm 1.4$ & $6.4 \pm 2.5$ & 1.1 & $>0.05$ & NS \\
\hline Inotropic support (hrs) & $12.2 \pm 4.6$ & $12.9 \pm 4.8$ & 0.58 & $>0.05$ & NS \\
\hline Total blood loss (ml) & $431.5 \pm 311.1$ & $447.17 \pm 355.2$ & 0.60 & $>0.05$ & NS \\
\hline Glucose level (before hospital discharge)(mg/dl) & $130.2 \pm 17.7$ & $147.3 \pm 38.5$ & 0.84 & $>0.05$ & NS \\
\hline Perioperative MI & $2(4.76 \%)$ & $2(5.26 \%)$ & 0.85 & $>0.05$ & NS \\
\hline Low cardiac output syndrome & $2(4.76 \%)$ & $3(7.89 \%)$ & 0.58 & $>0.05$ & NS \\
\hline Rhythmic complications & $7(16.66 \%)$ & $8(21.05 \%)$ & 0.45 & $>0.05$ & NS \\
\hline Haemorrhagic complications & $1(2.38 \%)$ & $1(2.63 \%)$ & 0.87 & $>0.05$ & NS \\
\hline Deep wound infection & $2(4.76 \%)$ & $3(7.89 \%)$ & 0.58 & $>0.05$ & NS \\
\hline Superficial wound infection & $3(7.14 \%)$ & $4(10.52 \%)$ & 0.58 & $>0.05$ & NS \\
\hline Respiratory complications & $6(14.28 \%)$ & $7(18.42 \%)$ & 0.58 & $>0.05$ & NS \\
\hline Acute renal failure & $1(2.38 \%)$ & $2(5.26 \%)$ & 0.58 & $>0.05$ & NS \\
\hline Postoperative IABP insertion & $1(2.38 \%)$ & $2(5.26 \%)$ & 0.58 & $>0.05$ & NS \\
\hline Overall hospital complications & $13(30.95 \%)$ & $14(36.84 \%)$ & 0.58 & $>0.05$ & NS \\
\hline Overall one-year survival & $40(95.23 \%)$ & $36(94.73 \%)$ & 0.85 & $>0.05$ & NS \\
\hline
\end{tabular}

\section{Discussion}

$\mathrm{HbAlc}$ is one of the most frequently studied parameters for outcome prediction in CABG surgery [6]. It reflects a patient's prevailing glycemia over the previous 2-3 months. Some researchers suggest that a decrease in the previously elevated level of HbAlc can be demonstrated even within 2 weeks of a change in therapy. HbAlc is influenced by various factors. The HbAlc test result may not be affected by short-term, even very significant glycemic variability (both hyperglycemia and hypoglycemia). HbAlc may be underestimated because of hemolytic anemia, posthemorrhagic anemia, renal failure, and drugs (e.g. erythropoietin, iron preparations, vitamin B12, anti-retroviral drugs). On the other hand, the level of HbAlc may be increased due to hypertriglyceridemia, hyperbilirubinemia, aplastic anemia, sideroblastic anemia, alcoholism, previous splenectomy, pregnancy, and medications (e.g. opiates, vitamin C, salicylates) [13]. It is recommend that for microvascular disease prevention the HbAlc goal should be less than 7\% (this level of $\mathrm{HbAlc}$ reflects an estimated average glucose level of $154 \mathrm{mg} / \mathrm{dl}$ equivalent to $8.6 \mathrm{mmol} / \mathrm{l}$ ) and in patients older than 70 years with diabetes lasting more than 20 years it should not exceed $8.0 \%$ [7].

Studies assessing the risk factors associated with outcomes after cardiac surgery suggested that perioperative high blood glucose levels are an independent predictor for postoperative morbidity and mortality. Levels of $\geq 7 \%$ indicate poor blood glucose control [18]. It has been claimed that high HbAlc levels are a strong predictor of mortality and morbidity independently of the patient's previous diabetic condition, and the mortality risk increases four-fold especially in coronary surgery cases when $\mathrm{HbAlc}$ levels are $>8.6 \%$. In other studies, it has been suggested that $\mathrm{HbAlc}$ is a strong predictor of morbidity and mortality in coronary surgery and that $\mathrm{HbAlc}$ levels $>7.03 \%$ increase the risk of postoperative complications [16]. Engorenet al. [19] and Halkos et al. [20] indicate in their articles the prognostic value of $\mathrm{HbAlc}$ testing in patients undergoing CABG. Hudson et al. [21] draw similar conclusions. They found higher mortality after elective cardiac surgery in patients with diabetes in whom preoperative $\mathrm{HbAlc}$ was greater than $6 \%$. They suggest that this test may be used as a screening tool for the assessment of operational risk. Again, although $\mathrm{HbA1c}$ values had been widely investigated worldwide as a reflective value of longterm blood glucose control and outcome predictor in diabetic patients, its predictive value in the surgical patient population did not receive a good attention [22].

Although some articles in the literature argue that high HbAlc levels increase mortality and morbidity, there are studies arguing that there is no relation between them [6]. Thus, this study is initiated prospectively to trace the outcome based on HbA1c values under strict precautions of tight glycemic control measures. In our study, results of postoperative morbidity and mortality were comparable with no statistical significance between both groups with higher than and lower than values of $\mathrm{HbA} 1 \mathrm{c} 8.6 \%$.

In our study, the demographic criteria of the studied groups were comparable with mean age of $60.34 \pm 6.81$ for group (I) and $61.65 \pm 6.53$ for group (II) with no statistical significance between them except for the chosen criterion of $\mathrm{HbAlc} \%$. Mean $\mathrm{HbA1c} \%$ value was $7.5 \pm 1.11 \%$ (range $7.00-8.6 \%$ ) for group (I) and $9.3 \pm 1.03 \%$ (range $8.6-10.3 \%$ ) for group (II) representing high statistical significance $(p<0.01)$. The study groups included morewomen $(62.5 \%)$ and cardiovascular risk factors including hypertension and dyslipidemia (with comparable insignificantly different ratios between the two study groups) and these data were in line with those of theliterature [30]. The prevalence of hypertensionin our study was high $(66.66 \%$, and $63.16 \%$ in group (I) and (II) respectively), comparable to that of the literature ( $49 \%$ to more than 60\%) [23] and so does the prevalenceof dyslipidemia (64.29\% and $73.68 \%$ in group (I) and (II) respectively) as compared to what is settled in the literature $(50 \%-70 \%)$ at the time of diagnosis according to Europeanstatistics [24]. Thus our study groups came homogenous and comparable with others studied in the literature. 
Improved perioperative blood glucose control and the use of insulin perfusion may contribute to improved operative outcomes in diabetic patients [25]. Kuhl et al. [26] in a study examining long-term outcomes after coronary bypass surgery in patients with type 2 diabetes mellitus suggested that mortality increased when HbAlc levels were $>9 \%$ and morbidity and complications increased when the levels were $>8.1 \%$. However, in the same study, mortality was not found to be associated with $\mathrm{HbAlc}$ levels in patients using insulin. In our study, we followed strict blood glucose controlling measures using insulin therapy in the immediate 7-10 days preoperatively, intra-operatively and postoperatively which reflected comparable statistically insignificant results between the study groups and patients with $\mathrm{HbA} 1 \mathrm{c}>8.6 \%$ did not suffer from additional serious adverse complications as compared with those having lower values.

In our study, intra-operative glucose levels were higher than preoperatively and they were even higher in group (II) than group (I) but with no statistical significance and with no significant adverse effect on intra-operative mortality, aortic cross clamping time, cardiopulmonary bypass (CPB) time, number of grafts done, blood glucose level (during and after $\mathrm{CPB}$ ), metabolic acidosis, haemodynamics, weaning off-CPB, inotropic support medications and intra-aortic balloon insertion although group (II) patients showed higher values. However, this was not a similar finding observed by Mona et al. [27] and Sato et al. [22]. Intra-operative insulin resistance and poor preoperative diabetic control had been studied by Sato and colleagues who concluded that in diabetic patients preoperative HbA1c levels predict insulin sensitivity during cardiac surgery and, possibly, outcome independent of the patient's diabetic state. Our results were attributed to proper strict glycemic control by insulin infusion and acidosis correction frequently with ABGs and blood sugar reading every 15 minutes.

Our study results agree with Bardiaet al. [28] who showed that postoperative complications and mortality were not related to HbAlc levels in patients undergoing isolated valve surgery. They found it remarkable that there was no association specifically between the postoperative glycaemic variability and the complications and emphasized that it was different from the previous findings in coronary patients. However, their conclusion is really interestingraising our inquiry about $\mathrm{HbAlc}$ that shows different predictions in valve and coronary surgeries in patients with open heart surgeries using cardiopulmonary bypass because it is well known that valve surgeries are associated with more complications than coronary surgeries. Baharet al. [29] in their retrospective study addressed our inquiry and had similar conclusion to ours. The percentage of overall hospital adverse complications in our study was $30.95 \%$ and $36.84 \%$ (for group (I) and (II) respectively, results that are similar to the retrospective study reported by Moursiet al. [30] who showed $31 \%$ in their diabetic group.

The operative mortality in our study was $2.5 \%(2.38 \%$ and $2.63 \%$ in group (I) and (II) respectively). It was $3 \%$ in the diabetic group and $1 \%$ in the non-diabetic group in the study reported by Moursi et al. [30] and in the studyreported by Thourani et al. [31], the operative mortality was significantly higher in the diabetic group than in the non-diabeticgroup (3.9\% vs $1.6 \%, p<0.0001)$. However, other studies reported more favorable results in diabetic patients with coronarysurgery. Szabo et al. [32] and Rajakaruna et al. [33] reported an operative mortality of $2.6 \%$ and $2.2 \%$ in diabetics compared to $1.6 \%$ and $1 \%$ respectively in non-diabetic patients. Our results can be explained by improved perioperative management andsurgical techniques and by the fact that the majority of our patients had fewer co-morbidities.

Higher levels of HbAlc in our study did not increase the incidence of perioperative myocardial infarction. This is consistent with the results from Iranian center study by Zahra Faritouset al. [6], Mona et al. [27], Moursi et al. [30] and Bahar et al. [29]. However, Knapiket al. [34] found a different result as they found a significant increase of postoperative myocardial infarction in patients with high levels of HbA1c.

Atrial fibrillation is a common complication post-cardiac surgery. In our study higher levels of HbAlc had no implication on rate of postoperative atrial fibrillation. On contrast, Halkoset al. [16] and Kinoshita et al. [35] found that atrial fibrillation rate increased with lower levels of $\mathrm{HbA} 1 \mathrm{c}$.

In the literature, female sex, high BMI, chronic respiratory insufficiency, diabetes and the use of both mammary arteries were the main risk factors for deep siteinfection [36]. Undoubtedly, one of the most dramatic improvements in outcome among diabetic patients has been the implementation of tight perioperative glucose control. Like we found in our study, Furnary and $\mathrm{Wu}$ [37] reported dramatic reductions in mortality and deep surgical wound infection among diabetic patients managed with a continuous insulin infusion initiated intra-operatively and maintained through the first 2 postoperative days. Moreover, no statistically significant differences emerged between our groups of the study. We attribute these improvements to enhanced myocardial glycometabolic function associated with near-euglycemic state achieved by tight glycemic measures aided by insulin therapy. Continuous insulin infusion was the rule to all patients in the operating theatre and in the ICU, while S. C. insulin according to Matias protocol [17] was given in the regular room both preoperatively and post-ICU transfer until hospital discharge. Similar to our results, Furnary and Wu [37] did not identify $\mathrm{HbA1c}$ as a risk factor for hospital mortality nor deep sternal wound infection. Again, other studies like those done by of Göksedef et al. [38], Matsuura et al. [39], Hudson et al. [21] and Alserius et al. [40] concluded that elevated $\mathrm{HbA}$ 1c has no role in increasing deep sternal wound infection. In contrary to our results, Halkoset al. [16] found a significant increase in rate of deep sternal wound infection with the increase of level of HbAlc.

In our study, we didn't find any significant increase of the rate of postoperative acute renal failure and neurological complications but Halkoset al. [16] and Hudson et al. [21] 
found that increased level of HbAlc was associated with increased rate of post operative renal failure. Furthermore, results obtained from Halkoset al. [16] shows a significant increase in rate of cerebrovascular stroke with increased level of $\mathrm{HbA1c}$.

Survival after coronary surgery is influenced by age, presence of cardiovascular riskfactors, extension of coronary artery disease, degree of left ventricular dysfunction, choice of grafts and their permeability. Filsoufiet al. [41] reported 1year and 5-year survival of $94.7 \%$ and $81.9 \%$ in diabetics and $95.4 \%$ and $85.9 \%$ in non-diabeticsrespectively; similarly, Alserius et al. [40] found a decrease in survival at 5 years in diabetic patients $(81.7 \%$ vs $90.6 \%)$. Razaet al. [36] reported survival after CABG among diabetic vs non-diabetic at 1, 5, 10 and 20 years of $94 \%$ vs $94 \%, 80 \%$ vs $84 \%, 56 \%$ vs $66 \%$, and $20 \%$ vs $32 \%$, respectively. Moursiet al. [30], during their follow-up period, reported one death in each group (diabetic and non-diabetic) and acomparable incidence of major cardiovascular events between the two groups $(24 \%$ and $17 \%$ ). In our study, we had one-year survival of $95.23 \%$ and $94.73 \%$ in group (I) and (II) respectively ( $p>0.05)$, and had one death in each group with overall mortality $5 \%$ (including both operative and one year follow-up).

\section{Conclusion}

The rising higher percentage of primary $\mathrm{CABG}$ patients with decompensated diabetes (patients with $\mathrm{HbAlc}>8.6 \%$ ) is really annoying and alarming. These data show how serious the problem of diabetes control is in patients with coronary disease scheduled for surgical treatment. Glycemia control has to be individualized for every patient before each operation. This means that the treatment has to be tailored to glycemia levels and checked often enough to maintain glucose equilibrium. In addition to that, the age of the patient and comorbidities have to be taken into consideration. Our results show that the routine preparation of each of those patients should include an HbAlc level check. We would like to conclude that although intensive perioperative insulin treatment is mandatory in every diabetic patient, it is also necessary to optimize the diabetes treatment before the operation. Optimal diabetic control before the cardiac operation results in lower morbidity and mortality. Although patients with IHD undergoing primary $\mathrm{CABG}$ and having decompensated diabetes with $\mathrm{HbA1c}$ values higher than $8.6 \%$ have more insulted cardiovascular condition, these higher HbAlc values do not add more additional impact on the proposed adverse intra- and postoperative complications as with lower values with the aid of strict (tight) glycemic control measures in the immediate preoperative period.

\section{Study Limitations}

The limitations of our study included the reduced number of the study population. During the follow-up, other elements were not specified, namely data on diabetes, hypertension, lipid profile, smoking habits and treatment tolerance.
Although we included known diabetic patients for almost 20 years, we could have never been sure of the actual duration (being subjective by the patient) and treatment tolerance. We did not involve type I diabetic patients as well. Follow-up survival was one year and as the negative influence of diabetes on long-term survival is largely related to the progression of comorbidities related to the effect of diabetes on the target organs [42], the rapid progression of the coronary disease and the appearance of new atherosclerotic lesions in the native vessel and finally the adverse effect of diabetes on endothelial function and on the permeability of the grafts, this underscores the importance of tertiary prevention to avoid or reduce the negative impact of diabetes on the progression of atherosclerotic disease.

\section{References}

[1] Flaherty JD, Davidson CJ. Diabetes and coronary revascularization. JAMA. 2005;293:1501-1508.

[2] Schwartz L, Kip KE, Frye RL, Alderman EL, Schaff HV, Detre KM. Bypass Angioplasty Revascularization Investigation Coronary bypass graft patency in patients with diabetes in the Bypass Angioplasty Revascularization Investigation (BARI) Circulation. 2002;106:2652-2658.

[3] Ouattara A, Lecomte P, Le Manach Y, Landi M, Jacqueminet S, Platonov I, et al. Poor intraoperative blood glucose control is associated with a worsened hospital outcome after cardiac surgery in diabetic patients. Anesthesiology. 2005;103:687-94.

[4] Lazar HL, Chipkin SR, Fitzgerald CA, Bao Y, Cabral H, Apstein CS. Tight glycemic control in diabetic coronary artery bypass graft patients improves perioperative outcomes and decreases recurrent ischemic events. Circulation. 2004;109:1497-502.

[5] Tennyson C, Lee R, Attia R. Is there a role for HbA1c in predicting mortality and morbidity outcomes after coronary artery bypass graft surgery? Interact CardiovascThorac Surg. 2013;17:1000-8.

[6] Faritous Z, Ardeshiri M, Yazdanian F, Jalali A, Totonchi Z, Azarfarin R. Hyperglycemia or high hemoglobin A1C: Which one is more associated with morbidity and mortality after coronary artery bypass graft surgery? Ann ThoracCardiovasc Surg. 2014;20:223-8.

[7] Inzucchi SE, Bergenstal RM, Buse JB, Diamant M, Ferrannini E. Management of hyperglycemia in type 2 diabetes: a patient- centered approach: position statement of the American Diabetes Association (ADA) and the European Association for the Study of Diabetes (EASD) Diabetes Care. 2012;35:1364-1379.

[8] Knapik P, Ciésla D, Filipiak K, Knapik M, Zembala M. Prevalence and clinical significance of elevated preoperative glycosylated hemoglobin in diabetic patients scheduled for coronary artery surgery. Eur J Cardiothorac Surg. 2011;39:484-9.

[9] Engoren M, Habib RH, Zacharias A, Schwann TA, Riordan CJ, Durham SJ, et al. The prevalence of elevated hemoglobin Alc in patients undergoing coronary artery bypass surgery. $\mathrm{J}$ CardiothoracSurg. 2008;3:63. 

Glycosylated Hemoglobin (HbA1c) in Tightly-Controlled Diabetic Patients Undergoing Primary CABG

[10] Subramaniam B, Lerner A, Novack V, Khabbaz K, ParyenteWiesmann $\mathrm{M}$, Hess $\mathrm{P}$, et al. Increased glycemic variability in patients with elevated preoperative $\mathrm{HbA1C}$ predicts adverseoutcomes following coronary artery bypass grafting surgery. AnesthAnalg. 2014;118:277-87.

[11] Anand SS, Razak F, Vuksan V, Gerstein HC, Malmberg K, Yi $\mathrm{Q}$, et al. Diagnostic strategies to detect glucose intolerance in a multiethnic population. Diabetes Care. 2003;26:290-6.

[12] Davidson MB, Schriger DL, Peters AL, Lorber B. Relationship between fasting plasma glucose and glycosylated hemoglobin: potential for false-positive diagnoses of type 2 diabetes using new diagnostic criteria. JAMA. 1999;281:1203-10.

[13] Reynolds TM, Smellie WS, Twomey PJ.Glycatedhaemoglobin (HbA1c) monitoring.BMJ. 2006;333:586-588.

[14] Roques F, Michel P, Goldstone AR. The logistic EuroSCORE. Eur Heart J. 2003;24:882-883.

[15] Shroyer AL, Coombs LP, Peterson ED, Eiken MC, DeLong ER, Chen A, Ferguson TB, Jr, Grover FL, Edwards FH, Society of Thoracic Surgeons The Society of Thoracic Surgeons: 30-day operative mortality and morbidity risk models. Ann Thorac Surg. 2003;75:1856-1864.

[16] Halkos ME, Puskas JD, Lattouf OM, Kilgo P, Kerendi F, Song HK, et al. Elevated preoperative hemoglobin A1c level is predictive of adverse events after coronary artery bypass surgery. J ThoracCardiovasc Surg. 2008 Sep;136:631-40.

[17] J. Blaha, P. Kopecky, M. Matias, R. Hovorka, J. Kunstyr, T. Kotulak, et al.:Comparison of three protocols for tight glycemic control in cardiac surgery patients. Diabetes Care, 32 (5) (2009), pp. 757-761.

[18] Masla M, Gottschalk A, Durieux ME, Groves DS. HbA1c and diabetes predict perioperative hyperglycemia and glycemic variability in on-pump coronary artery bypass graft patients. $\mathrm{J}$ CardiothoracVascAnesth. 2011;25:799-803.

[19] Engoren M, Habib RH, Zacharias A, Schwann TA, Riordan CJ. The prevalence of elevated hemoglobin A1c in patients undergoing coronary artery bypass surgery. J Cardiothorac Surg. 2008;3:63.

[20] Halkos ME, Lattouf OM, Puskas JD, Kilgo P, Cooper WA, Morris CD, Guyton RA, Thourani VH. Elevated preoperative hemoglobin Alc level is associated with reduced long-term survival after coronary artery bypass surgery. Ann Thorac Surg. 2008;86:1431-1437.

[21] Hudson CC, Welsby IJ, Phillips-Bute B, Mathew JP, Lutz A, Chad Hughes G, Stafford-Smith M, Cardiothoracic Anesthesiology Research Endeavors (C. A. R. E.) Group Glycosylated hemoglobin levels and outcome in non-diabetic cardiac surgery patients. Can J Anesth. 2010;57:565-572.

[22] H. Sato, G. Carvalho, T. Sato, R. Lattermann, T. Matsukawa, T. Schricker: The association of preoperative glycaemic control, intraoperative insulin sensitivity and outcomes after cardiac surgery. J ClinEndocrinolMetab, 95 (2010), pp. 43384344.

[23] Nilsson PM, Cederholm J, Zethelius BR. Trends in blood pressure control in patients with type 2 diabetes: data from the Swedish National Diabetes Register (NDR). Blood Press 2011;20:34854
[24] Halimi S. Dyslipidemia of diabetes and insulin resistance.Nephrologie 2000;21(7):345-6.

[25] WahbyEhab A, Abo Elnasr Mohamed M, Eissa Michael I, Mahmoud Sahbaa M. Perioperative glycemic control in diabetic patients undergoing coronary artery bypass graft surgery. J Egypt SocCardiothorac Surg. 2016;24:143-9.

[26] Kuhl J, Sartipy U, Eliasson B, Nyström T, Holzmann MJ. Relationship between preoperative hemoglobin A1c levels and long- term mortality after coronary artery bypass grafting in patients with type 2 diabetes mellitus. Int $\mathrm{J}$ Cardiol. 2016;202:291-6.

[27] MonaRamadan, AhmedAbdelgawad, AhmedElshemy, EmadSarawy, AlyEmad, MahmoudMazen, AhmedAbdel Aziz. Impact of elevated glycosylated hemoglobin on hospital outcome and 1 year survival of primary isolated coronary artery bypass grafting patients. The Egyptian Heart Journal. Volume 70, Issue 2, June 2018, Pages 113-118.

[28] Bardia A, Khabbaz K, Mueller A, Mathur P, Novack V, Talmor D, et al. The Association Between Preoperative Hemoglobin A1C and Postoperative Glycemic Variability on 30-Day Major Adverse Outcomes Following Isolated Cardiac Valvular Surgery. AnesthAnalg. 2017;124:16-22.

[29] BaharAydınlı, AslıDemir, HarunÖzmen, ÖzdenVezir, UtkuÜnal, and Mustafa Özdemir. Can Pre-Operative HbA1c Values in Coronary Surgery be a Predictor of Mortality? Turk J AnaesthesiolReanim. 2018 Jun; 46(3): 184-190.

[30] I. Moursi, K. Al Fakharany. Prognosis of diabetic coronary artery bypass graft surgerypatients. Journal of the Egyptian Society of Cardio-Thoracic Surgery 25 (2017) 294-300.

[31] Thourani VH, Weintraub WS, Stein B, et al. Influence of diabetes mellitus on early and late outcome after coronary artery bypass grafting. Ann ThoracSurg 1999;67:104552.

[32] Szabo Z, Håkanson E, Svedjeholm R, et al. Early postoperative outcome and medium term survival in 540 diabetic and 2239 non diabetic patients undergoing coronary artery bypass grafting. Ann ThoracSurg 2002;74:7129.

[33] Rajakaruna C, Rogers CA, Suranimala C. The effect of diabetes mellitus on patients undergoing coronary surgery: a riskeadjusted analysis. J ThoracCardiovascSurg 2006;132. 80210.

[34] P. Knapik, D. Ciesla, K. filipiak, M. Knapik, M. Zembala. Prevalence and clinical significance of elevated preoperative glycosylated hemoglobin in diabetic patients scheduled for coronary artery surgery. Eur J CardiothoracSurg, 39 (2011), pp. 484-489.

[35] T. Kinoshita, T. Asai, T. Suzuki, A. Kambara, K. Matsubayashi. Preoperative hemoglobin Alc predicts atrial fibrillation after off-pump coronary artery bypass surgery. Eur J CardiothoracSurg, 41 (2012), pp. 102-107.

[36] Raza S, Sabik JF, Masabni K, et al. Surgical revascularization techniques that minimize surgical risk and maximize late survival after coronary artery bypass grafting in patients with diabetes mellitus. J ThoracCardiovascSurg 2014;148:1257-66.

[37] A. P. Furnary, Y. Wu. Eliminating the diabetic disadvantage: the Portland diabetic project. SeminThoracCardiovascSurg, 18 (2006), pp. 302-308. 
[38] D. Göksedef, S. Ömeroğlu, E. Yalvaç, M. Bitargil, G. İpek. Is elevated $\mathrm{HbA1c}$ a risk factor for infection after coronary artery bypass grafting surgery. Turk $\mathrm{J}$ ThoracCardiovascSurg, 18 (2010), pp. 252-258.

[39] K. Matsuura, M. Imamaki, A. Ishida, H. Shimura, Y. Niitsuma, M. Miyazaki. Off-pump coronary artery bypass grafting for poorly controlled diabetic patients. Ann ThoracSurg, 15 (2009), pp. 18-22.

[40] T. Alserius, R. Anderson, N. Hammar, T. Nordqvist, T. Ivert. Elevated glycosylated haemoglobin (HbAlc) is a risk marker in coronary artery bypass surgery. ScandCardiovasc J, 42 (2008), pp. 392-398.
[41] Filsoufi F, Rahmaniana PB, Castillo JG, et al. Diabetes is not a risk factor for hospital mortality following contemporary coronary artery bypass grafting. Interact CardiovascThoracSurg 2007;6:753-8.

[42] Leavitt BJ, Sheppard L, Maloney C, et al. Effect of diabetes and associated conditions on long-term survival after coronary artery bypass graft surgery. Circulation 2004;110. II414. 